\title{
A Multicenter Retrospective Survey of Poisoning after Consumption of Products Containing Synthetic Chemicals in Japan
}

\author{
Yoshito Kamijo ${ }^{1}$, Michiko Takai ${ }^{1}$, Yuji Fujita ${ }^{2}$, Yasuo Hirose ${ }^{3}$, Yasumasa Iwasaki ${ }^{4}$, \\ Satoshi Ishihara ${ }^{5}$, Takashi Yokoyama ${ }^{6}$, Keiichi Yagi ${ }^{7}$ and Tetsuya Sakamoto ${ }^{8}$
}

\begin{abstract}
Objective We conducted a multicenter retrospective survey of patients poisoned by synthetic chemicals (SCs) in Japan.

Methods Letters were sent to 467 emergency facilities requesting participation in the study, and questionnaires were mailed to facilities that agreed to participate.

Patients The study participants were patients who were transported to emergency facilities between January 2006 and December 2012 after consuming SC-containing products.

Results We surveyed 518 patients from 60 (12.8\%) facilities. Most patients were male (82.0\%), in their 20s or $30 \mathrm{~s}(80.5 \%)$, and had inhaled SCs $(87.5 \%)$ contained in herbal products $(86.0 \%)$. Harmful behavior was observed at the scene of poisoning for 56 patients $(10.8 \%)$, including violence to others or things in 32 , traffic accidents in seven, and self-injury or suicide attempts in four. Other than physical and neuropsychiatric symptoms, some patients also had physical complications, such as rhabdomyolysis (10.0\%). Of the 182 patients $(35.1 \%)$ admitted to hospitals, including 29 (5.6\%) who needed respirators, all of the $21(4.1 \%)$ hospitalized for at least seven days were male, and 20 had physical complications (rhabdomyolysis, 12; liver dysfunction, 5; renal dysfunction, 11; and physical injuries, 3). Most patients (95.6\%) completely recovered, although $10(1.9 \%)$ were transferred to a psychiatric department or hospital, and three $(0.6 \%)$ were handed over to the police due to combative or violent behavior. SCs such as synthetic cannabinoids, synthetic cathinones, or methoxetamine were detected in 20 product samples.

Conclusion Consuming products containing SCs can result in physical complications, including rhabdomyolysis, injuries, and physical or neuropsychiatric symptoms, which may require active interventions, such as respirator use or prolonged hospitalization.
\end{abstract}

Key words: synthetic cannabinoid, synthetic cathinone, methoxetamine, rhabdomyolysis, renal dysfunction

(Intern Med 53: 2439-2445, 2014)

(DOI: 10.2169/internalmedicine.53.2344)

\section{Introduction}

Synthetic chemicals (SCs), such as synthetic cannabi- noids, synthetic cathinones, or methoxetamine, have recently gained popularity as recreational drugs, especially among younger generations $(1,2)$. Products containing SCs are packaged and sold on the Internet or in shops under various

\footnotetext{
${ }^{1}$ Department of Emergency and Critical Care Medicine, School of Medicine, Kitasato University, Japan, ${ }^{2}$ Poisoning and Drug Laboratory Division, Critical Care and Emergency Center, Iwate Medical University Hospital, Japan, ${ }^{3}$ Emergency and Critical Care Medical Center, Niigata City General Hospital, Japan, ${ }^{4}$ Department of Emergency and Critical Care Medicine, Hiroshima University Hospital, Japan, ${ }^{5}$ Hyogo Emergency Medical Center, Japan, ${ }^{6}$ Department of Nephrology and Dialysis, Sapporo Higashi-Tokushukai Hospital, Japan, ${ }^{7}$ Emergency and Critical Care Medical Center, Yokohama City Minato Red Cross Hospital, Japan and ${ }^{8}$ Department of Emergency Medicine, School of Medicine, Teikyo University, Japan

Received for publication December 17, 2013; Accepted for publication March 30, 2014

Correspondence to Dr. Yoshito Kamijo, yk119@kitasato-u.ac.jp
} 

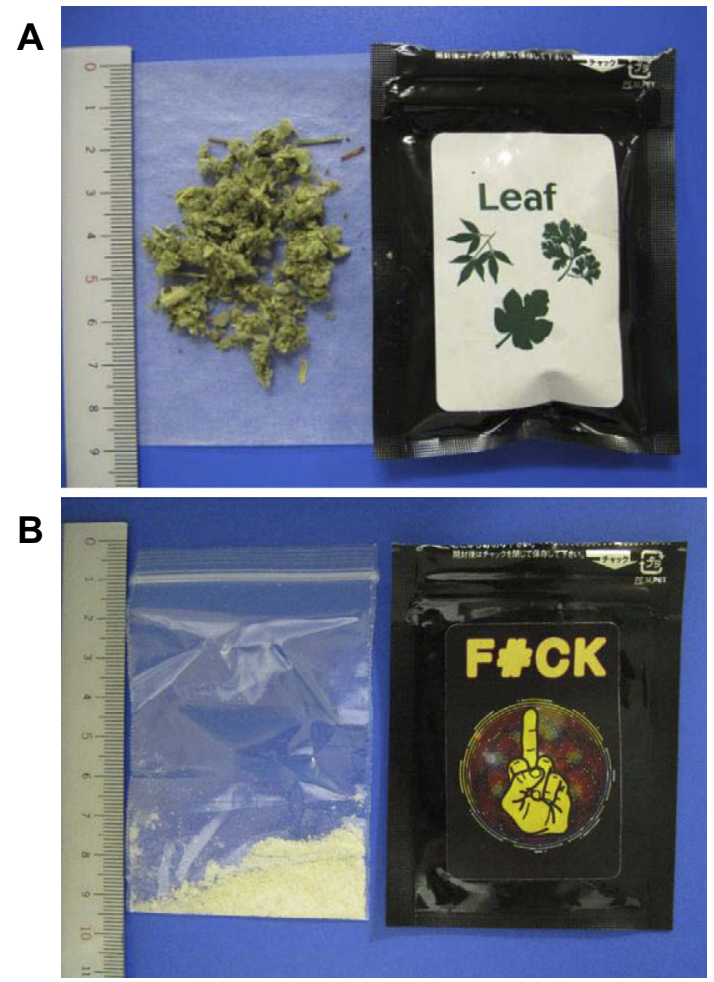

Figure. Samples of products commercialized as an "herb" (A) or a "bath salt" (B).

names, such as "herbs," "incense," or "bath salts" (Figure) $(3,4)$. Although such products are not sold for human consumption, they are in fact smoked to create a cannabislike high or ingested for euphoria and relaxation. One key to their popularity is that they are not detectable with conventional urine drug screening tests for amphetamines (AMP) or delta-9-tetrahydrocannabinol $\left(\Delta^{9}\right.$-THC), the primary psychoactive constituent of natural cannabis $(1,2)$.

The consumption of products containing SCs may have serious adverse effects. However, very little is known about this topic, and existing published studies have only assessed a small number of cases or limited data from poison centers in Europe or the United States (5-10). Here, we conducted a multicenter retrospective survey of the demographics, clinical features, treatments, and the outcomes of patients poisoned by SCs in Japan.

\section{Materials and Methods}

The study participants were patients who were transported to emergency facilities between January 2006 and December 2012 after consuming products containing SCs. A letter requesting participation was sent to 467 emergency facilities with employees who are members of the Japanese Society for Clinical Toxicology (JSCT) or the Japanese Association for Acute Medicine (JAAM). A total of 60 (12.8\%) facilities agreed to participate. A questionnaire was mailed to all participating facilities with questions regarding patient age and sex; how the products were obtained; the form of the product; route of intake; any chemicals taken together that affect the central nervous system (CNS); who called the ambulance; harmful behavior to self, others, or things at the scene; vital and clinical signs and symptoms, and physical complications on arrival at emergency facilities; treatments (including respirator use and administered drugs); outcomes; and toxicological analysis of the products or biological samples (e.g., blood or urine). The questionnaires were collected and analyzed at the Department of Emergency \& Critical Care Medicine, School of Medicine, Kitasato University. This study was approved by the ethics committees of the participating hospitals.

\section{Results}

\section{Patients}

A total of 521 patients from 60 emergency facilities in Japan were evaluated. A patient who refused to see a physician and two patients who fled from the hospital before seeing a physician were excluded. Thus, a total of 518 patients poisoned with SCs were included in this survey. The number of patients poisoned with SCs exponentially increased from 1 in 2010 and 48 in 2011 to 469 in 2012, although there were no patients until 2009. Men ( $n=425,82.0 \%)$ were 4.57 times more likely to be poisoned by SCs than women $(\mathrm{n}=93,18 \%)$.

\section{Sociodemographics}

Most patients were young [mean age, 28.4 years (SD 8.4 years)], with those in their twenties and thirties comprising $80.5 \%$ of the study population; those younger than 20 years accounted for only $9.3 \%$. The only patient younger than 10 years was a one-year-old boy who ingested his father's herbal products. A total of 202 patients provided information regarding how the products were obtained; 84 patients $(41.6 \%)$ purchased them in shops, $56(27.7 \%)$ obtained them from others, $39(19.3 \%)$ bought them on the Internet, and $27(13.4 \%)$ obtained them through other means, such as vending machines. Of the 450 patients who provided information regarding the form of the products, 387 (86.0\%) consumed herbs, $26(5.8 \%)$ powders, 24 (5.3\%) liquids, and $11(2.4 \%)$ more than two forms. Among 480 patients who provided information regarding routes of intake, 420 $(87.5 \%)$ inhaled SCs contained in the products that were vaporized by heating, $31(6.5 \%)$ ingested, six (1.3\%) sniffed, seven $(1.5 \%)$ inserted anally, and $11(2.4 \%)$ used more than two routes. Of the 406 patients who provided information regarding substances with CNS effects taken together with SC-containing products, 96 (23.6\%) drank alcohol and 20 (4.9\%) used psychotropic drugs [among which 17 (4.1\%) used benzodiazepines (BZO)]. Out of the 515 patients for whom the ambulance was called, $187(36.3 \%)$ called for themselves, whereas eyewitnesses, including passers-by, called for 102 patients (19.8\%), police officers for 40 (7.7\%), and others including family and friends for 186 (36.1\%). Among all patients, harmful behavior toward self, 
Table 1. Vital Signs on Admission $(n=518)$

\begin{tabular}{lllll}
\hline $\begin{array}{l}\text { Respiration rate } \\
(/ \mathrm{min})(\mathrm{n}=439)\end{array}$ & $\leq 19$ & $20-29$ & $30-39$ & $40-49$ \\
\hline $\begin{array}{l}\text { Pulse rate } \\
(\text { beats/min) }(\mathrm{n}=497)\end{array}$ & $196(44.6 \%)$ & $202(46.0 \%)$ & $30(6.9 \%)$ & $11(2.5 \%)$ \\
\hline $\begin{array}{l}\text { Systolic blood pressure } \\
(\mathrm{mmHg})(\mathrm{n}=501)\end{array}$ & $<80$ & $60-99$ & $100-139$ & $140 \leq$ \\
& $4(0.8 \%)$ & $348(69.5 \%)$ & $136(27.1 \%)$ & $13(2.6 \%)$ \\
\hline $\begin{array}{l}\text { GCS } \\
(\mathrm{n}=511)\end{array}$ & $3-8$ & $239(48.1 \%)$ & $205(41.2 \%)$ & $36(7.2 \%)$ \\
\hline $\begin{array}{l}\text { Pupil }(\mathrm{mean} \text { diameter}) \\
(\mathrm{mm})(\mathrm{n}=419)\end{array}$ & $\leq 2.0$ & $9-14$ & 15 & $180 \leq$ \\
& $10(2.4 \%)$ & $212(50.6 \%)$ & $197(47.0 \%)$ & \\
\hline $\begin{array}{l}\text { Body temperature } \\
\left({ }^{\circ} \mathrm{C}\right)(\mathrm{n}=469)\end{array}$ & $<35.0$ & $35.0 \leq,<37.0$ & $37.0 \leq,<38.5$ & $38.5 \leq$ \\
\hline
\end{tabular}

GCS: Glasgow Coma Scale

Table 2. Clinical Symptoms Other than Abnormal Vital Signs, and Physical Complications on Admission Frequently Seen in Patients $(n=518)$

\begin{tabular}{lll}
\hline Clinical symptoms & Number & $\%$ \\
\hline Vomiting & 129 & 24.9 \\
Agitation, irritability & 122 & 23.6 \\
Nausea & 81 & 15.6 \\
Palpitation & 75 & 14.5 \\
Anxiety, fear & 54 & 10.4 \\
Confusion & 48 & 9.3 \\
Abnormal behavior & 33 & 6.4 \\
Seizure, convulsion & 30 & 5.8 \\
Panic attack & 14 & 2.7 \\
Psychosis (hallucinations, delusions) & 14 & 2.7 \\
Chest pain, chest discomfort & 9 & 1.7 \\
Syncope & 8 & 1.5 \\
Tremor & 5 & 1.0 \\
\hline Physical complications & Number & $\%$ \\
\hline Rhabdomyolysis & 52 & 10.0 \\
Renal dysfunction & 25 & 4.8 \\
Liver dysfunction & 25 & 4.8 \\
Physical injuries & 9 & 1.7 \\
\hline
\end{tabular}

others, or items at the scene was observed in 56 patients $(10.8 \%)$, including violence to others or things in $32(6.2 \%)$, traffic accidents in seven $(1.4 \%)$, and self-injury or suicide attempts in four $(0.8 \%)$.

\section{Clinical features}

With respect to vital signs on admission, many patients had tachypnea with a respiratory rate $\geq 20 / \mathrm{min}(55.4 \%$ ), tachycardia with a pulse rate $\geq 100$ beats/min (48.5\%), hypertension with a systolic blood pressure $\geq 140 \mathrm{mmHg}$ (29.7\%), consciousness disturbance with a Glasgow Coma Scale (GCS) score $\leq 14(46.0 \%)$, and mydriasis with a mean pupil diameter $\geq 4 \mathrm{~mm}(47.0 \%)$. Some patients had severe tachycardia with a pulse rate $\geq 140$ beats/min $(7.2 \%)$, severe hypertension with a systolic blood pressure $\geq 180 \mathrm{mmHg}$
(2.6\%), severe disturbance of consciousness with a GCS $\leq 8$ $(6.5 \%)$, and hyperthermia with a body temperature $\geq 38.5^{\circ} \mathrm{C}$ (2.6\%). In contrast, only a few patients had bradycardia with a pulse rate $<60$ beats/min $(3.4 \%)$, hypotension with a systolic blood pressure $<80 \mathrm{mmHg}(0.8 \%)$, miosis with a mean pupil diameter $\leq 2 \mathrm{~mm}(2.4 \%)$, and hypothermia with a body temperature $<35.0^{\circ} \mathrm{C}(4.3 \%)$ (Table 1$)$. The clinical symptoms on admission other than abnormal vital signs included neuropsychiatric symptoms with high morbidity, such as agitation or irritability (23.6\%), anxiety or fear (10.4\%), confusion $(9.3 \%)$, abnormal behavior $(6.4 \%)$, and seizures or convulsions $(5.8 \%)$, as well as vomiting $(24.9 \%)$, nausea (15.6\%), and palpitations (14.5\%). The major physical complications on admission included rhabdomyolysis (10.0\%), liver dysfunction (4.8\%), renal dysfunction (4.8\%), and physical injuries $(1.7 \%$ ) (Table 2).

\section{Treatments and outcomes}

Treatments for patients were as follows: respirators (29, $5.6 \%$ ), infusions $(454,87.6 \%)$, and drugs including propofol, BZO (e.g., midazolam, diazepam, and flunitrazepam), antipsychotics (e.g., haloperidol and risperidone), and dexmedetomidine $(76,14.7 \%)$ (Table 3$)$.

Among all patients, 182 (35.1\%) were admitted to hospitals with a mean length of hospitalization of 3.2 days (SD 5.6 days). Most patients completely recovered $(n=495$, $95.6 \%), 10(1.9 \%)$ were discharged with residual signs or symptoms, $10(1.9 \%)$ were transferred to a psychiatric department or hospital, and three $(0.6 \%)$ were handed over to the police due to combative or violent behavior (Table 4).

All of the 21 patients $(4.1 \%)$ hospitalized for at least seven days were male, and 20 (Cases 1 to 20) had physical complications on admission: 12 had rhabdomyolysis [including two with notably elevated creatine kinase levels (>100,000 IU/L)], five had liver dysfunction, 11 had renal dysfunction, and three had physical injuries from traffic ac- 
Table 3. Treatments $(n=518)$

\begin{tabular}{|c|c|c|c|c|}
\hline \multicolumn{2}{|l|}{ Treatment } & \multicolumn{2}{|l|}{ Number } & $\%$ \\
\hline \multicolumn{2}{|l|}{ Respirator } & \multicolumn{2}{|l|}{29} & 5.6 \\
\hline \multicolumn{2}{|l|}{ Infusion } & \multicolumn{2}{|l|}{454} & 87.6 \\
\hline \multirow{2}{*}{\multicolumn{4}{|c|}{$\begin{array}{l}\text { Medication } \\
\text { (drugs administered to multiple patients) }\end{array}$}} & 14.7 \\
\hline & & & & \\
\hline & propofol & & 21 & \\
\hline & diazepam & & 14 & \\
\hline & midazolam & & 12 & \\
\hline & metoclopramide & & 6 & \\
\hline & haloperidol & & 4 & \\
\hline & risperidone & & 3 & \\
\hline & dopamine & & 3 & \\
\hline & flunitrazepam & & 2 & \\
\hline & dexmedetomidine & & 2 & \\
\hline Observation & nly & 49 & & 9.5 \\
\hline
\end{tabular}

Table 4. Patient Outcomes $(n=518)$

\begin{tabular}{lr}
\hline Outpatients & 336 \\
Complete recovery & 323 \\
Residual signs and symptoms & 5 \\
Transfer to psychiatric department or hospital & 6 \\
Transfer to police & 2 \\
& \\
Admitted patients & 182 \\
Duration of hospitalization & \\
1 day & 75 \\
2-3 days & 80 \\
$4-6$ days & 6 \\
$\geq 7$ days & 21 \\
Complete recovery & 5 \\
Residual signs or symptoms & 4 \\
Transfer to psychiatric department or hospital & 1 \\
Transfer to police & \\
\hline
\end{tabular}

Table 5. Physical Complications on Admission for Patients Admitted for $\geq 7$ Days

\begin{tabular}{|c|c|c|c|c|}
\hline Case & Age & Gender & Complications & Data \\
\hline 1 & 41 & M & RM & CK 2,536 IU / L \\
\hline 2 & 30 & M & RM, Hyponatremia & CK 1,516 IU / L, Na $115 \mathrm{mEq} / \mathrm{L}$ \\
\hline 3 & 26 & M & $\mathrm{RD}$ & $\mathrm{Cr} 1.27 \mathrm{mg} / \mathrm{dL}$ \\
\hline \multirow[t]{2}{*}{4} & 25 & M & $\mathrm{LD}, \mathrm{RD}$ & GOT / GPT 1,356 / 357 IU / L, Cr $1.43 \mathrm{mg} / \mathrm{dL}$ \\
\hline & & & $\mathrm{RM}$ & CK $102,571 \mathrm{IU} / \mathrm{L}$ \\
\hline 5 & 24 & M & \multicolumn{2}{|c|}{ SAH and SDH (Traffic accident) } \\
\hline 6 & 27 & M & $\mathrm{RD}, \mathrm{RM}$ & Cr 1.46 mg / dL, CK 2,060 IU / L \\
\hline \multirow[t]{2}{*}{7} & 30 & M & $\mathrm{LD}, \mathrm{RD}$ & GOT / GPT 329 / 97 IU / L, Cr 2.1 mg / dL \\
\hline & & $\mathrm{RM}$ & & CK 28,929 IU / L \\
\hline 8 & 52 & M & $\mathrm{RD}$ & $\mathrm{Cr} 1.59 \mathrm{mg} / \mathrm{dL}$ \\
\hline 9 & 27 & M & Respiratory dysfunction & $\mathrm{pH} 6.935, \mathrm{PaCO}_{2} 146$ Torr \\
\hline 10 & 31 & M & $\mathrm{RM}$ & CK $712 \mathrm{IU} / \mathrm{L}$ \\
\hline \multirow[t]{2}{*}{11} & 23 & M & $\mathrm{LD}$ & GOT / GPT 3,378 / $501 \mathrm{IU} / \mathrm{L}, \mathrm{Cr} 5.09 \mathrm{mg} / \mathrm{dL}$ \\
\hline & & $\mathrm{RM}$ & & CK 601,920 IU / L \\
\hline 12 & 59 & M & $\mathrm{LD}, \mathrm{RM}$ & GOT / GPT 467 / $102 \mathrm{IU} / \mathrm{L}, \mathrm{CK} 41,183 \mathrm{IU} / \mathrm{L}$ \\
\hline 13 & 31 & M & $\mathrm{RD}, \mathrm{RM}$ & Cr $1.3 \mathrm{mg} / \mathrm{dL}, \mathrm{CK} 3,168 \mathrm{IU} / \mathrm{L}$ \\
\hline \multirow[t]{2}{*}{14} & 30 & M & $\mathrm{RD}, \mathrm{RM}$ & $\mathrm{Cr} 1.5 \mathrm{mg} / \mathrm{dL}, \mathrm{CK} 2,340 \mathrm{IU} / \mathrm{L}$ \\
\hline & & \multicolumn{3}{|c|}{ Multiple fractures (Traffic accident) } \\
\hline 15 & 40 & M & $\mathrm{RD}, \mathrm{RM}$ & $\mathrm{Cr} 1.3 \mathrm{mg} / \mathrm{dL}, \mathrm{CK} 510 \mathrm{IU} / \mathrm{L}$ \\
\hline \multirow[t]{2}{*}{16} & 32 & M & $\mathrm{LD}, \mathrm{RD}$ & GOT / GPT 155 / 38 IU / L, Cr 1.98 mg / dL \\
\hline & & $\mathrm{RM}$ & & CK $15,981 \mathrm{IU} / \mathrm{L}$ \\
\hline 17 & 24 & M & $\mathrm{RD}$ & $\mathrm{Cr} 1.29 \mathrm{mg} / \mathrm{dL}$ \\
\hline 18 & 23 & M & $\mathrm{RD}$ & $\mathrm{Cr} 2.35 \mathrm{mg} / \mathrm{dL}$ \\
\hline 19 & 23 & M & \multicolumn{2}{|c|}{ Deep wrist cutting (Suicide attempt) } \\
\hline 20 & 51 & M & \multicolumn{2}{|c|}{ Multiple fractures (Traffic accident) } \\
\hline 21 & 23 & $\mathrm{M}$ & \multicolumn{2}{|c|}{ Non } \\
\hline
\end{tabular}

LD: liver dysfunction, M: male, RD: renal dysfunction, RM: rhabdomyolysis, SAH: subarachnoid hemorrhage, SDH: subdural hemorrhage

cidents or suicide attempts. The remaining patient (Case 21) exhibited signs of psychosis and was transferred to a psychiatric hospital (Table 5).

\section{Toxicological analysis}

Triage DOA $^{\circledR}$ [a conventional urine drug screening test for abused drugs (Biosite Diagnostics Inc., San Diego, USA)] was performed in 267 patients and was positive in 62 (23.2\%): phencyclidine (PCP) in three, tricyclic antidepressants (TCA) in four, BZO in 31, barbiturates (BAR) in 14, opiates (OPI) in nine, cannabinoids $\left(\Delta^{9}-\mathrm{THC}\right)$ in 11 , and
AMP in 5. Although no patient underwent toxicological analysis of biological samples (e.g., blood or urine) other than Triage $\mathrm{DOA}^{\circledR}, 20$ samples of the products consumed by 14 patients, including one (Case 21) in Table 5, were analyzed using gas chromatography mass spectrometry (GC/ MS) at two emergency facilities. Synthetic cannabinoids were detected in 12 samples, synthetic cathinones in 13, and methoxetamine in seven (Table 6). Case 21 was found to consume two products containing a total of five synthetic cannabinoides. 
Table 6. Synthetic Chemicals Detected in 20 Samples of the Products

\begin{tabular}{|c|c|c|c|c|}
\hline Form & Synthetic cannabinoids & Synthetic cathinones & Other & $\begin{array}{l}\text { Case in } \\
\text { Table5 }\end{array}$ \\
\hline Herb & & MePHP & Methoxetamine & \\
\hline Herb & XLR-11 & MePHP & Methoxetamine & \\
\hline Herb & $\begin{array}{l}\text { MAM-2201, XLR-11, UR-144 } \\
\text { JWH122N-(4-pentenyl) analog }\end{array}$ & MePHP & Methoxetamine & \\
\hline Herb & $\mathrm{AKB}-48$ & Pentedrone & & \\
\hline Herb & $\begin{array}{l}\text { MAM-2201 } \\
\text { JWH-122N-(4-pentenyl) analog }\end{array}$ & МePHP & Methoxetamine & \\
\hline Herb & 5-fluoro PB-22, PB-22 & & & \\
\hline Herb & JWH-081, JWH-122 & & & 21 \\
\hline Herb & $\begin{array}{l}\text { JWH-210 } \\
\text { AM-694, AM-2201 }\end{array}$ & & & 21 \\
\hline Herb & MAM-2201, AM-2232, UR-144 & $\alpha$-PVP & & \\
\hline Herb & MAM-2201, XLR-11, UR-144 & $\alpha-P V P$ & & \\
\hline Powder & & & Methoxetamine & \\
\hline Powder & & MDPPP & & \\
\hline Powder & & $\alpha-P V P$ & & \\
\hline Powder & & & Methoxetamine & \\
\hline Powder & & $\alpha-P V P$ & & \\
\hline Powder & & Pentedrone & & \\
\hline Powder & & $\alpha$-PVP & Methoxetamine & \\
\hline Powder & XLR-11, UR-144 & MePHP & & \\
\hline Powder & MAM-2201 & & & \\
\hline & JWH-122N-(4-pentenyl) analog & & & \\
\hline Powder & AB-PINACA & & & \\
\hline
\end{tabular}

\section{Discussion}

In the present survey, there were no instances of patients being transported to emergency facilities after consuming SC-containing products until 2009, and there were only sporadic cases between 2010 and 2011. However, the incidence dramatically increased in 2012. The Ministry of Health, Labour, and Welfare (MHLW) reported that the number of shops selling these products in Japan has increased markedly since October 2011, with a total of 389 shops (including 94 in Tokyo and 73 in Osaka) existing as of March 31, 2012 (11). This proliferation of shops likely contributed, at least in part, to the increase in the number of patients in 2012.

In the present study, most patients were men (82.0\%) in their $20 \mathrm{~s}$ or $30 \mathrm{~s}(80.5 \%)$, with adolescents younger than 20 years comprising only $9.3 \%$ of all patients. In Europe and the United States, the highest prevalence of SC use is reported among males and youths. The proportions of adolescents under 20 years poisoned by SCs in Europe and the United States were much higher than that in the present survey $(9.3 \%)$, with adolescents accounting for $41 \%$ of total SC exposures reported to poison centers in Texas (5-7), $42 \%$ reported to the poison center in Sweden (9), and 67\% to the poison center in Ireland (10). Adolescents in Japan may be less likely to use or have access to SCs compared to those in Europe and the United States. In August 2008, the MHLW announced the third Five-Year Strategy aimed to prevent drug abuse, with a particular focus on measures di- rected at adolescents. For instance, books containing abundant information about the risks and hazards of SCs were created and distributed to parents of sixth-grade elementary school students, third-grade junior high school students, and both employed and unemployed adolescents (11). Healthcare education regarding the adverse effects of SCs for adolescents may be more effective in Japan.

In the present study, SCs such as synthetic cannabinoids, synthetic cathinones, or methoxetamine were detected in many samples of the consumed products (Table 6). These products possibly contained different SC components with variable potencies and concentrations. In Japan, many efforts have been made to decrease the use of SC-containing products. To this end, the MHLW regulates chemical substances that are scientifically proven to induce psychiatric toxicity and have narcotic-like behavior (i.e., causes mental or physical dependency) under the Narcotics and Psychotropics Control Act. If a chemical substance is classified as a narcotic, its possession, consumption, import, compound manufacture, and sale are prohibited. However, a chemical substance cannot be immediately classified as a narcotic, as this requires scientific research into its potential harmful effects, which requires considerable effort and cost. As of December 2012, only four synthetic cannabinoids (i.e., JWH-018, JWH-073, JWH-122, and cannabicyclohexanol) and one synthetic cathinone (MDPV), among all SCs found in products sold on the Internet or in shops as legal herbal blends, incense, or bath salts, were classified as narcotics in Japan. The MHLW also regulates chemical substances that are harmful to human health via their excitatory or hallucinogenic effects 
and classifies them as controlled drugs under the Pharmaceutical Affairs Act. While the import, compound manufacture, and sale of chemical substances classified as controlled drugs are prohibited, their possession and consumption are not. It also takes less time to classify such substances as controlled drugs. As of December 2012, 99 chemical substances have been classified as controlled drugs, all of which are synthetic cannabinoids except $\alpha$-pyrrolidinovalerophenone (PVP), a synthetic cathinone. New chemical substances are likely to be synthesized to replace those classified as "narcotics" or "controlled drugs," presenting a cyclical problem with no resolution (12), and regulations focusing solely on synthetic cannabinoids may contribute to the spread of alternative synthetic cathinones and methoxetamine in Japan.

Synthetic cannabinoids, many of which have chemical structures unrelated to $\Delta^{9}$-THC, are full agonists of CNS cannabinoid type $1\left(\mathrm{CB}_{1}\right)$ receptors, and are thus more potent than $\Delta^{9}$-THC, a partial agonist of these receptors. As a result, synthetic cannabinoids may have stronger adverse effects than natural cannabis (13-16), including agitation, aggressive behavior, inability to speak, short-term memory deficits, drowsiness, panic attacks, psychosis, hallucinations, delusions, confusion, seizures, dizziness, mydriasis, nausea, vomiting, chest pain, and heart palpitations (3, 5-10, 17, 18). The management of poisoning was largely supportive of an excellent prognosis. The majority of those who reported to poison centers in Europe and the United States had selflimited symptoms and only received symptomatic treatment. Intravenous fluid administration was the most common therapeutic intervention, followed by BZOs to manage neuropsychiatric symptoms, such as agitation or seizures (5-9).

Methoxetamine, 2-(3-methoxyphenyl)-2-(ethylamino)cyclohexanone, is a derivative of ketamine and acts as an $\mathrm{N}$ methyl-D-aspartate (NMDA) antagonist and dopamine reuptake inhibitor with greater potency, a longer delay in onset, and a longer duration of action than ketamine (19). The adverse effects associated with its use include dissociative symptoms such as derealization, depersonalization, and catatonic-like state; sympathomimetic symptoms including tachycardia, hypertension, mydriasis, agitation, aggression, hallucinations, confusion, and stupor; and cerebellar symptoms such as gait instability, slurred speech, incoordination, dysarthria, dysdiadochokinesis, and nystagmus (19-23). Several patients have been hospitalized after using methoxetamine for recreational purposes $(21,22)$. Treatment is supportive with BZOs for sedation, anti-emetics, intravenous fluids for rhabdomyolysis and dehydration, and physical restrain and respiratory support as required (24).

Synthetic cathinones are phenylalkylamine derivatives that inhibit the reuptake of norepinephrine, serotonin, and dopamine, as well as stimulate the release of these monoamines, producing an AMP-like effect to exert both excitatory and sympathomimetic symptoms $(25,26)$. The adverse effects include agitation, combative or violent behavior, psychosis, hallucinations, delusion, paranoia, confusion, suicidal ideation, tachycardia, chest pains, hyperten- sion, dehydration, cardiovascular complications, rhabdomyolysis, and even death (27-29). In a Michigan study conducted by the Centers for Disease Control and Prevention from November 13, 2010 to March 31, 2011, 17 of the 35 emergency room patients exposed to synthetic cathinones were hospitalized, and one was dead upon arrival at the emergency room (30). Spiller et al. reported that death $(n=1)$ was included among severe medical outcomes of 236 patients exposed to MDPV (31). Furthermore, a review of the literature describing poisoning with synthetic cathinones revealed that multi-organ failure, including rhabdomyolysis, renal failure, and hepatic failure, and death, can occur in severe cases (32). The primary treatment of agitation in the emergency room should commence with BZOs, which are well tolerated, allow titration, and can prevent and terminate seizures. However, if agitation involves psychosis, an antipsychotic may be useful to augment BZO treatment. Persistent hypertension can be treated with vasodilators, such as nitroglycerine or sodium nitroprusside. As multiple organ systems may be affected, laboratory testing should include electrolytes administration, hepatic and renal function measurements, a coagulation panel, and creatine kinase assessments to screen for rhabdomyolysis (33). Synthetic cathinones may induce more severe toxicity requiring more active therapeutic interventions and resulting in worse outcome than synthetic cannabinoids or methoxetamine.

In the present survey, many patients exhibited sympathomimetic symptoms such as tachycardia, hypertension, and mydriasis and neuropsychiatric symptoms including agitation or irritability, seizures or convulsions, and psychosis, which can be attributed to synthetic cannabinoids, synthetic cathinones, or methoxetamine. However, a number of patients $(5.6 \%)$ required respirators, and a few patients $(1.9 \%)$ were transferred to a psychiatric department or hospital. The physical complications, such as rhabdomyolysis and physical injuries, apparently contributed to prolonged hospitalization. Although the products consumed by the patients with severe physical complications were not analyzed, the consumption of products containing synthetic cathinones may have contributed to the higher toxicity rate observed in this study.

\section{Limitations}

The determination of SC exposure was based on information or products provided by patients, their families, or friends or products found at the scene by first responders. However, SC exposure was not verified by the analysis of biological samples, such as blood or urine. Moreover, 20 samples analyzed toxicologically do not represent all of the samples consumed by patients in this study.

\section{Conclusion}

The use of SC-containing products can lead to serious adverse effects and cause physical complications, such as rhabdomyolysis and physical injuries due to harmful behavior (e.g., violence, traffic accidents, self-injury, or suicide at- 
tempts), as well as severe physical or neuropsychiatric symptoms that may require active interventions, such as respirator use or prolonged hospitalization.

The authors state that they have no Conflict of Interest (COI).

\section{Acknowledgement}

We thank the 60 emergency facilities in Japan for providing data. This work was supported by a Grant-in-Aid for Research on Regulatory Science of Pharmaceuticals and Medical Devices from the Ministry of Health, Labour and Welfare.

\section{References}

1. Schneir AB, Cullen J, Ly BT. "Spice" girls: synthetic cannabinoid intoxication. J Emerg Med 40: 296-299, 2011.

2. Vearrier D, Osterhoudt K. A teenager with agitation-higher than she should have climbed. Pediatr Emerg Care 26: 462-464, 2010.

3. Vardakou I, Pistos C, Spiliopoulou C. Spice drugs as a new trend: mode of action, identification and legislation. Toxicol Lett 197: 157-162, 2010.

4. Hermanns-Clausen M, Sauer O, Gerber G, et al. New "herbal drugs" of abuse: spice and smoke. Clin Toxicol 47: 452, 2009.

5. Forrester MB, Kleinschmidt K, Schwarz E, Young A. Synthetic cannabinoid exposures reported to Texas Poison Centers. J Addict Dis 30: 351-358, 2011.

6. Forrester MB. Adolescent synthetic cannabinoid exposures reported to Texas poison centers. Pediatr Emerg Care 28: 985-989, 2012

7. Forrester MB, Kleinschmidt K, Schwarz E, Young A. Synthetic cannabinoid and marijuana exposures reported to poison centers. Hum Experi Toxicol 31: 1006-1011, 2012.

8. Hoyte CO, Jacob J, Monte AA, Al-Jumaan M, Bronstein AC, Heard KJ. A characterization of synthetic cannabinoid exposures reported to the National Poison Data System in 2010. Ann Emerg Med 60: 435-438, 2012.

9. Westerbergh J, Hulten P. Novel synthetic cannabinoids, CRA 13, JWH-015, JWH-018 and JWH-210 - detected in a case series. Clin Toxicol 49: 222, 2011.

10. Herbert JX, Duggan E, Tracey JA. The effect of legislation on synthetic cannabinoid abuse in Ireland. Clin Toxicol 49: 240, 2011

11. http://www.mhlw.go.jp/stf/seisakunitsuite/bunya/kenkou_iryou/ iyakuhin/yakubuturanyou/index.html [Accessed 1 September, 2014].

12. Fattore L, Fratta W. Beyond THC: the new generation of cannabinoid designer drugs. Front Behav Neurosci 5: 60, 2011.

13. Atwood BK, Huffman J, Straiker A, Makcie K. JWH-018, a common constituent of 'Spice' herbal blends, is a potent and efficacious cannabinoid CB1 receptor agonist. Br J Pharmacol 160: 585-593, 2010.

14. Wintermeyer $\mathrm{A}$, Moller $\mathrm{I}$, Thevis $\mathrm{M}$, et al. In vitro phase I metabolism of the synthetic cannabimimetic JWH-018. Ann Bioanal Chem 398: 2141-2153, 2010.

15. Jerry J, Collins G, Streem D. Synthetic legal intoxicating drugs: The emerging 'incense' and 'bath salt' phenomenon. CCJM 79: 258-264, 2012.
16. Uchiyama N, Kikura-Hanajiri R, Ogata J, Goda Y. Chemical analysis of synthetic cannabinoids as designer drugs in herbal products. Forensic Sci Int 198: 31-38, 2010.

17. Fernandez MC, Roth B, Villarreal CL. Fake marijuana causing real problems in Texas. Clin Toxicol 49: 212-213, 2011.

18. Cohen J, Morrison S, Greenberg J, Saidinejad M. Clinical presentation of intoxication due to synthetic cannabinoids. Pediatrics 129: e1064-e1067, 2012.

19. Corazza O, Assi S, Schifano F. From "Special K" to "Special M": the evolution of the recreational use of ketamine and methoxetamine. CNS Neurosci Ther 19: 454-460, 2013.

20. Jansen KLR. Near-death experiences and the NMDA receptor. BMJ 298: 1708, 1989.

21. Schields JE, Dargan PI, Wood DM, Puchnarewicz M, Davies S, Waring WS. Methoxetamine associated reversible cerebellar toxicity: Three cases with analytical confirmation. Clin Toxicol 50: 438-440, 2012.

22. Wood DM, Davies S, Puchnarewicz M, Johnston A, Dargan PI. Acute toxicity associated with the recreational use of the ketamine derivative methoxetamine. Eur J Clin Pharmacol 68: 853-856, 2012.

23. Wood DM, Dargan PI. Novel psychoactive substances: how to understand the acute toxicity associated with the use of these substances. Ther Drug Monit 34: 363-367, 2012.

24. Loeffler G, Craig C. Methoxetamine misuse and toxicity. J Stud Alcohol Drugs 74: 816-817, 2013.

25. Coppola M, Mondola M. 3, 4-Methylenedioxypyrovalerone (MDPV): chemistry, pharmacology, and toxicology of a new designer drug of abuse marketed online. Toxicol Lett 208: 12-15, 2012.

26. Prosser JM, Nelson LS. The toxicology of bath salts: a review of synthetic cathinones. J Med Toxicol 8: 33-42, 2012.

27. Wright TH, Cline-Parhamovich K, Lajoie D, Parsons L, Dunn M, Ferslew KE. Deaths involving methylenedioxyprovalerone (MDPV) in upper east Tennessee. J Forensic Sci 58: 1558-1562, 2013.

28. Murray BL, Murphy CM, Beuhler MC. Death following recreational use of designer drug "bath salts" containing 3, 4methylenedioxypyrovalerone (MDPV). J Med Toxicol 8: 69-75, 2012.

29. Ross EA, Reisfield GM, Watson MC, Chronister CW, Goldberger BA. Psychoactive "bath salts" intoxication with methylenedioxypyrovalerone. Am J Med 125: 854-858, 2012.

30. Centers for Disease Control and Prevention. Emergency department visits after use of a drug sold as "bath salts" - Michigan, November 13, 2010-March 31, 2011. Morb Mortal Wkly Rep 60: 624-627, 2011

31. Spiller HA, Ryan ML, Weston RG, Jansen J. Clinical experience with and analytical confirmation of "bath salts" and "legal highs" (synthetic cathinones) in the United States. Clin Toxicol 49: 499505, 2012.

32. Miotto K, Striebel J, Cho AK, Wang C. Clinical and pharmacological aspects of bath salt use: a review of the literature and case reports. Drug Alcohol Depend 132: 1-12, 2013.

33. Wilson MP, Pepper D, Currier GW, Holloman Jr. GH, Feifel D. The psychopharmacology of agitation: consensus statement of the American association for emergency psychiatry project Beta psychopharmacology workgroup. West J Emerg Med 13: 26-34, 2012.

(C) 2014 The Japanese Society of Internal Medicine http://www.naika.or.jp/imonline/index.html 